\title{
Isolated Frontal Sinusitis and Anosmia: A Novel Presentation
}

\author{
P. K. Purushothaman ${ }^{1}$ (1) Saniya Ahmed ${ }^{1} \cdot$ Keerthini Arun $^{1} \cdot$ Alkis James Psaltis $^{2}$
}

Received: 19 October 2020/ Accepted: 24 November 2020/Published online: 2 January 2021

(C) Association of Otolaryngologists of India 2021

\begin{abstract}
Isolated frontal sinus disease is a rare and highly morbid condition. Although chronic frontal sinusitis has been described in literature, clinically it is quite uncommon in the absence of paranasal sinusitis and rhinitis. Here we examine a case of isolated chronic frontal sinusitis presenting with anosmia - a curious clinical manifestation.
\end{abstract}

Keywords Frontal sinus - Anosmia - Olfaction .

Olfactory dysfunction · Isolated frontal sinusitis

\section{Introduction}

Of all the paranasal sinuses, the frontal sinus remains the single most daunting sinus in terms of management and long-term disease control. It presents the most variable anatomy in terms of pneumatization and drainage pathway and is also the narrowest sinus with close approximation to the orbit and skull base [1]. In the published literature, complications of frontal sinusitis take the spotlight which includes Pott's puffy tumour, intracranial and orbital infections. Given its anterior location, its influence on olfaction is seldom considered. This report discusses one such case.

P. K. Purushothaman

entpurush@gmail.com

1 Department of Otorhinolaryngology and Head and Neck Surgery, SRM Medical College Hospital and Research Centre, Chengalpattu, Tamil Nadu, India

2 Head of Department, Otolaryngology Head and Neck Surgery, The Queen Elizabeth Hospital, The University of Adelaide, Adelaide, Australia

\section{Case Report}

A 51 years old female presented with mild frontal headache for 5 years, in the absence of other symptoms such as vomiting, visual disturbances or seizures. In the 2 months preceding her presentation to the ENT surgeon she also reported reduced smell perception. Her olfactory disturbance was insidious in its development and a daily phenomenon lasting throughout the day. It was this symptom that prompted her to consult a neurologist. With no history of head trauma, previous surgery or other sinonasal symptoms, she was referred for an MRI Brain. The MRI demonstrated isolated bilateral frontal sinus disease with no other sinus or intracranial involvement and she was therefore referred to our care.

ENT examination demonstrated frontal sinus tenderness on palpation. Neurological exam was unremarkable other than complete absence of olfactory perception.

Diagnostic nasal endoscopy showed polypoid changes of anterior end of middle turbinate. There was no visible pus or polyposis involving the middle meatus.

CT Paranasal sinus confirmed bilateral frontal sinus opacification with intra-sinus hyper densities. There was an absence of the intersinus septum but the anterior and posterior frontal tables remained intact (Fig. 1). All other paranasal sinuses were well aerated and free of obvious disease. The presence of hyperdensities favoured fungal sinusitis as the most likely diagnosis.

The patient underwent ESS under general anaesthesia. Frontal recess was approached by the Axillary flap and Intact bulla technique [2, 3]. Inspissated pus and secretions were cleared from the frontal sinus. There was no fungal or allergic mucin present in the sinus. On inspection the mucosa was found to be congested and oedematous. 
Fig. 1 CT PNS showing the isolated involvement of bilateral frontal sinuses
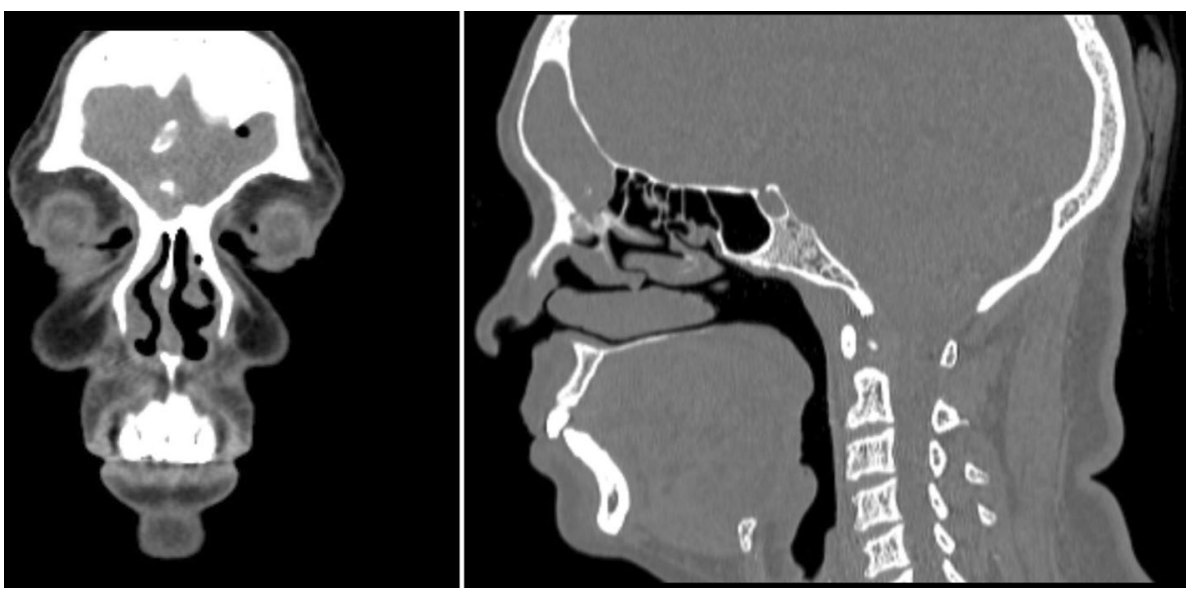

Finally, both frontal sinuses were irrigated with betamethasone and gentamicin solution.

Post op administration of IV antibiotics and IV Dexamethasone was given for 3 days.

CT done 1 month later, demonstrated complete resolution of the frontal sinus opacification (Fig. 2).

On follow-up at 6 weeks, the patient's headache had resolved, with restoration of sense of smell.

The histopathology report showed pseudostratified ciliated columnar epithelium with underlying stroma showing interstitial oedema and mixed inflammatory infiltrates. There was no evidence of granulomas. The report confirmed the diagnosis of chronic frontal sinusitis.

\section{Discussion}

Isolated frontal sinusitis is a rare entity and typically presents with symptoms of frontal headache, nasal discharge and in some cases associated frontal swelling.

Olfactory disturbance can be seen following URTI, head trauma, patients with anterior cranial fossa pathology and neurodegenerative diseases. Although it is commonly observed in widespread sinusitis in up to $60-80 \%$ of patients, it is rarely reported in isolated frontal sinusitis [4].

In sinusitis, smell disturbance is attributed to respiratory mucosa oedema decreasing the airflow to the olfactory cleft; classifying them as transport disorders. However, several studies have shown effectiveness of steroids in improving olfaction, and biopsy of neuroepithelium in sinusitis shows histologic abnormalities, suggesting them to be a sensory disorder also [5]. A study by Lane AP et al proposes 3 mechanisms by which olfactory dysfunction may occur in chronic rhinosinusitis. They suggest that the inflammatory marker- TNF- $\alpha$ affects the signalling efficacy of neurons. Chronic exposure of olfactory neuroepithelium to cytokines causes olfactory neuron degeneration and the inability to regenerate and replace the lost neurons during ongoing inflammatory process. They also found the olfactory dysfunction to be reversible i.e. neuronal regeneration occurred once the inflammation stopped [6]. However, this reasoning may not completely apply to a case where the frontal sinus alone is involved. There was no significant inflammation of the nasal mucosa to prevent odorants from reaching the olfactory cleft. The olfactory neuroepithelium also appeared normal during nasal endoscopy.
Fig. 2 Post Op CT PNS showing patent frontal sinus drainage pathway

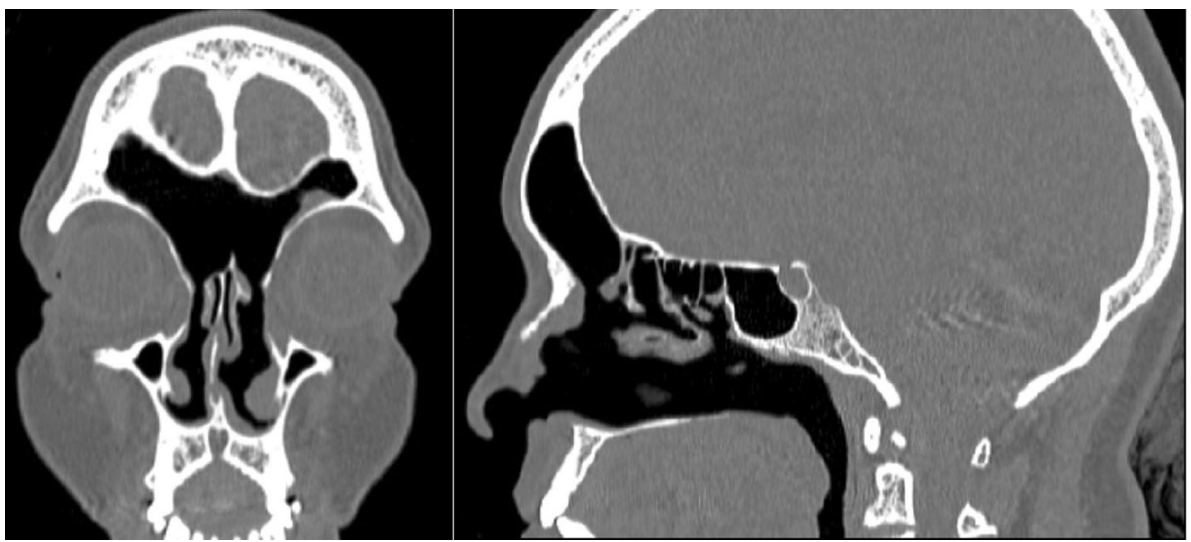


Our case is the first to our knowledge that reports a complete loss of sense of smell as a result of isolated frontal sinusitis. Although the mechanism remains unclear due to the remote location of frontal sinus inflammation to the posterior olfactory epithelium, we postulate that irritation/inflammation of the olfactory bulbs/first olfactory neurons may have been responsible. Complete restoration of sense of smell following surgical drainage of the frontal sinus infection supports this hypothesis. Several articles have noted improvement of olfaction following surgical management of Chronic Rhinosinusitis [7-9].

Smell disturbances are usually overlooked in the clinical setting and more importance given to symptoms like facial pain, nose block or discharge. Anosmia has recently gained increased recognition during the COVID-19 pandemic, being considered as one of its characteristic features [10]. We must remember that smell plays a vital role in sensing gas leaks, fires, spoiled food and also taste; affecting the nutritional intake of the individual. Anosmia due to sinonasal disease is probably the most treatable form of olfactory dysfunction.

Our patient received prior counselling regarding the uncertainty of regaining normal olfaction after the procedure. Fortunately, the patient was able to perceive all smells except for faint odours at 6 months post op.

Olfactory loss is a difficult issue to evaluate. The aetiology often remains obscure. Therapeutic options are limited and are rarely effective. This case demonstrates that isolated frontal sinusitis may also present with anosmia. The purpose of this paper is to inform about an atypical presentation of an uncommon condition and to stress the importance of a detailed clinical history, complete nasal examination and radiological imaging. Having these tools in our arsenal will help early detection and avoid a poor prognosis.

Funding This clinical report received no specific grant from any funding agency.

\section{Compliance with Ethical Standards}

Conflicts of interest The authors declare that they have no conflict of interest.
Consent for publication Informed Patient Consent was obtained.

Ethical Approval This article does not contain any study with human participants or animals by any of the authors.

\section{References}

1. Duvoisin B, Schnyder P (1992) Do abnormalities of the frontonasal duct cause frontal sinusitis? A CT study in 198 patients. AJR Am J Roentgenol. 159(6):1295-1298. https://doi.org/10.2214/ajr.159.6.1442405

2. Wormald PJ (2002) The axillary flap approach to the frontal recess. Laryngoscope. 112(3):494-499. https://doi.org/10.1097/00005537-200203000-00016

3. Loury MC (1993) Endoscopic frontal recess and frontal sinus ostium dissection. Laryngoscope. 103(4 Pt 1):455-458. https://doi.org/10.1002/lary.5541030417

4. Banglawala SM, Oyer SL, Lohia S, Psaltis AJ, Soler ZM, Schlosser RJ (2014) Olfactory outcomes in chronic rhinosinusitis with nasal polyposis after medical treatments: a systematic review and meta-analysis. Int Forum Allergy Rhinol. 4(12):986-994. https://doi.org/10.1002/alr.21373

5. Raviv JR, Kern RC (2004) Chronic sinusitis and olfactory dysfunction. Otolaryngol Clin North Am. 37(6):1143-vi. https://doi.org/10.1016/j.otc.2004.06.003

6. Lane AP, Turner J, May L, Reed R (2010) A genetic model of chronic rhinosinusitis-associated olfactory inflammation reveals reversible functional impairment and dramatic neuroepithelial $\begin{array}{lll}\text { reorganization. } & \text { 30(6):2324-2329. }\end{array}$ https://doi.org/10.1523/JNEUROSCI.4507-09.2010

7. Kohli P, Naik AN, Farhood Z et al (2016) Olfactory outcomes after endoscopic sinus surgery for chronic rhinosinusitis: a metaanalysis. Otolaryngol Head Neck Surg. 155(6):936-948. https://doi.org/10.1177/0194599816664879

8. Delank KW, Stoll W (1998) Olfactory function after functional endoscopic sinus surgery for chronic sinusitis. Rhinology. 36(1):15-19

9. DeConde AS, Mace JC, Alt JA, Schlosser RJ, Smith TL, Soler ZM (2014) Comparative effectiveness of medical and surgical therapy on olfaction in chronic rhinosinusitis: a prospective, multi-institutional study. Int Forum Allergy Rhinol. 4(9):725-733. https://doi.org/10.1002/alr.21350

10. Meng X, Deng Y, Dai Z, Meng Z (2020) COVID-19 and anosmia: A review based on up-to-date knowledge. Am J Otolaryngol. 41(5):102581. https://doi.org/10.1016/j.amjoto.2020.102581

Publisher's Note Springer Nature remains neutral with regard to jurisdictional claims in published maps and institutional affiliations. 